\title{
Antibody-like CD95 Receptor/Fc-fusion Protein CAN-008
}

National Cancer Institute

\section{Source}

National Cancer Institute. Antibody-like CD95 Receptor/Fc-fusion Protein CAN-008. NCI

Thesaurus. Code C90562.

A human, soluble fusion protein consisting of the extracellular domain of the CD95 receptor fused to the Fc-domain of the human IgG antibody, with potential antineoplastic activity. Upon administration, antibody-like CD95 receptor/Fc-fusion protein CAN-008 binds to the CD95 ligand (CD95L) and blocks the binding of CD95L to the CD95 receptor. In tumor cells, blockage of CD95L-mediated signaling pathways may prevent cell migration and invasive cell growth; in healthy cells, blockage of CD95L-mediated signaling pathways may prevent apoptosis and may protect cell damage. Activation of the CD95 receptor plays an important role in the initiation of apoptosis in healthy cells or the invasive growth of cancer cells. 